\title{
Hamman's syndrome triggered by the onset of type 1 diabetes mellitus accompanied by diabetic ketoacidosis
}

\author{
Shinji Kamei ${ }^{1} \cdot$ Hideaki Kaneto $^{1} \cdot$ Akihito Tanabe $^{1} \cdot$ Ryo Shigemoto $^{1} \cdot$ \\ Shintaro Irie ${ }^{1} \cdot$ Yurie Hirata $^{1} \cdot$ Maiko Takai $^{1} \cdot$ Kenji Kohara $^{1} \cdot$ Masashi Shimoda $^{1}$. \\ Tomoatsu Mune ${ }^{1} \cdot$ Kohei Kaku'
}

Received: 18 May 2016/Accepted: 23 May 2016/Published online: 13 June 2016

(c) The Author(s) 2016. This article is published with open access at Springerlink.com

\section{Dear Editor,}

Hamman's syndrome, which is also known as spontaneous pneumomediastinum, could be induced in various situations such as labor and delivery [1]. The potential mechanism for Hamman's syndrome is as follows: The vulnerability of alveolar walls by some reason increases air pressure, which leads to alveolar rupture. Then, spilled air peels the connective tissue and finally enters into mediastinal space through pulmonary hilum. Hamman's syndrome is one of the relatively rare pulmonary diseases, and there are few reports showing the case of Hamman's syndrome triggered by the onset of type 1 diabetes mellitus accompanied by diabetic ketoacidosis. However, recently we experienced three cases of young male subjects with Hamman's syndrome triggered by the onset of type 1 diabetes mellitus accompanied by diabetic ketoacidosis. These cases are very rare, and there were many similarities among these three cases.

Clinical characteristics of these three cases were as follows: age (years old): 29, 20, 20 (case 1, case 2, case 3); gender: male, male, male; HbA1c (\%): 12.0, 12.3, 6.9; plasma glucose level (mg/dL): 1298, 1543, 783; pH: 6.89, 7.10, 7.24; total ketone body concentration in blood ( $\mu \mathrm{mol} /$ L): 1662, 20,960, 15,500; acetoacetic acid ( $\mu \mathrm{mol} / \mathrm{L}): 734$, 5080, 2960; 3-hydroxybutyric acid ( $\mu \mathrm{mol} / \mathrm{L})$ : 928, 15,880, 12,540; WBC (/mL): 37,370, 27,590, 7050; CRP (mg/dL):

Managed by Antonio Secchi.

Shinji Kamei

s.kamei@med.kawasaki-m.ac.jp

1 Department of Diabetes, Metabolism and Endocrinology, Kawasaki Medical School, 577 Matsushima, Kurashiki 701-0192, Japan
$4.01,<0.03,0.76$, respectively. Type of diabetes in all three subjects was type $1 \mathrm{~A}$, and the autoantibodies of the pancreas were positive: anti-GAD antibody $(\mathrm{U} / \mathrm{mL}): 157.7,3.0$, 1.5 (case 1 , case 2, case 3); anti-IA-2 antibody (U/mL): 2.6 , 5.6, $<0.4$, respectively. Marked reduction in body weight was observed: BMI on admission $\left(\mathrm{kg} / \mathrm{m}^{2}\right): 25.1,13.7,19.0$; BMI before the onset of type 1 diabetes $\left(\mathrm{kg} / \mathrm{m}^{2}\right): 29.3,17.2$, 21.7; recent weight loss ( $\mathrm{kg} /$ duration): $10 \mathrm{~kg} / 1$ month, $11 \mathrm{~kg} / 2$ weeks, $8 \mathrm{~kg} / 1$ week, respectively. All three cases experienced vomiting very frequently, and case 1 and 2, but not case 3, experienced chest pain. On physical examination, subcutaneous emphysema was observed in all three cases. In chest X-ray, pneumomediastinum was observed in these three cases (red arrows) (Fig. 1). Also, in computed tomography, such pneumomediastinum was confirmed in these three cases (red circles) (Fig. 1). In case 1, pneumonia image was observed in lower right lung field (blue arrows and blue circle). In addition, subcutaneous emphysema was observed in all cases.

We immediately started antibiotics therapy in order to prevent the progression of inflammation. Mediastinal emphysema image in chest X-ray disappeared in several days after starting the therapy. The number of days required for the disappearance of emphysema image in these three cases was 4, 9 and 5 days, respectively. The number of days until the complete recovery was 15,9 and 6 days, respectively. There were no sequelae and no recurrence of emphysema at all in all cases.

It is thought that in cases with diabetic ketoacidosis air pressure could be increased by Kussmaul's breathing or repeated vomiting $[2,3]$. Therefore, we think that repeated vomiting might have triggered the onset of Hamman's syndrome in these three subjects. In addition, decrease in pulmonary surfactant observed with diabetic ketone acidosis could lead to the vulnerability of alveolar walls [4]. 
Fig. 1 Chest X-ray (upper panels) and computed tomography (middle and lower panels) in three cases with Hamman's syndrome triggered by the onset of type 1 diabetes mellitus accompanied by diabetic ketoacidosis. Pneumomediastinum is observed in these three cases (red arrows and red circles). In case 1 , pneumonia image is observed in lower right lung field (blue arrows and blue circle) case 1

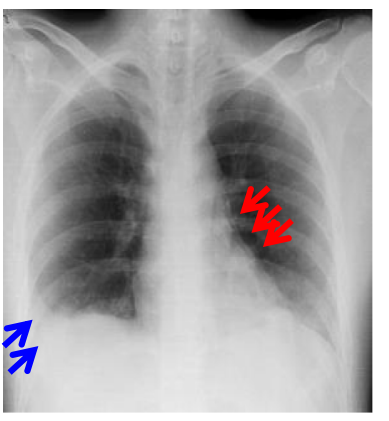

case 2
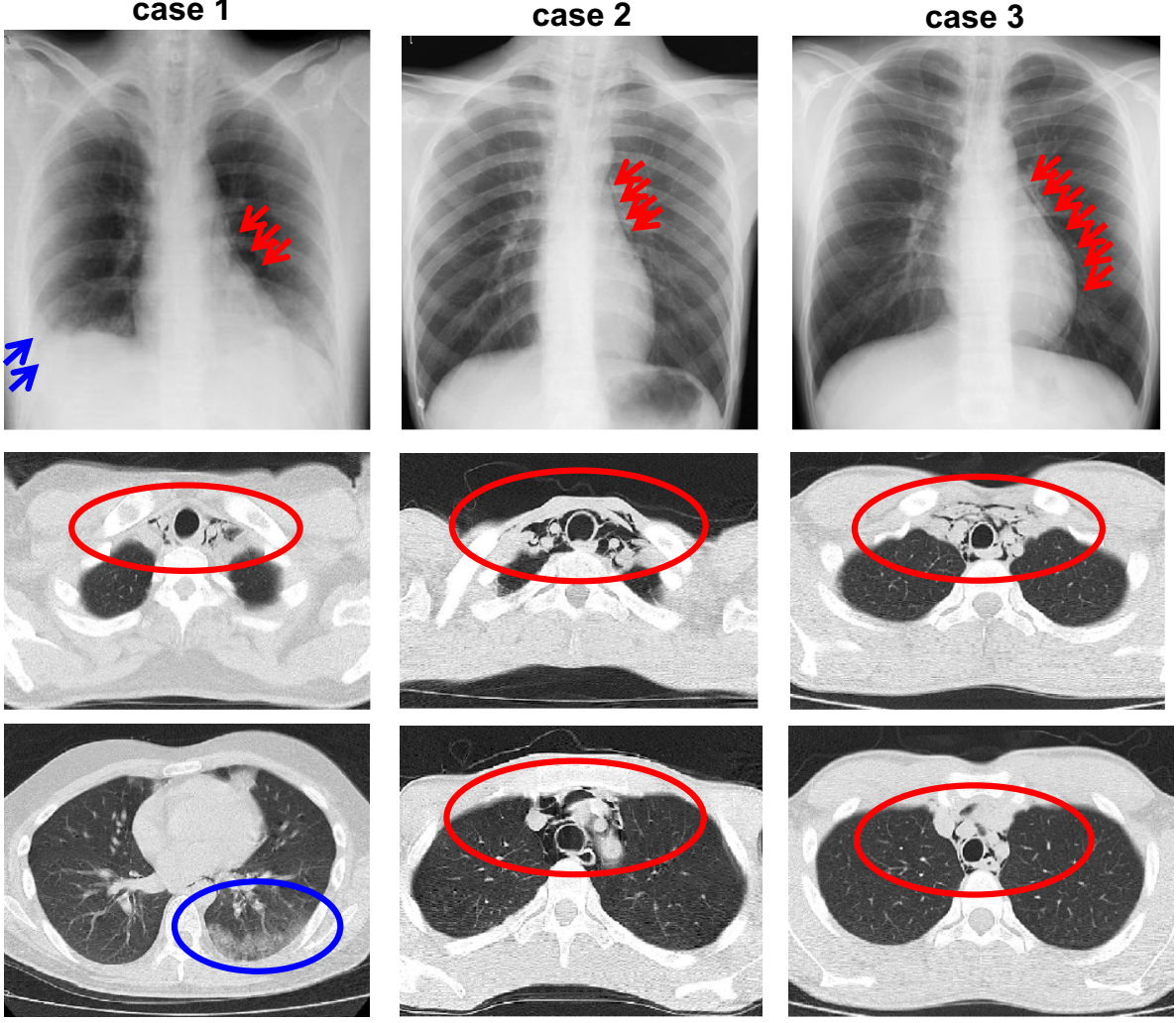

Therefore, although speculative, such phenomena might have been also involved in the onset of Hamman's syndrome in these cases.

In conclusion, we should be aware of the possibility that Hamman's syndrome is induced by the onset of type 1 diabetes mellitus accompanied by diabetic ketoacidosis. Since such pneumomediastinum sometimes becomes very severe and leads to a fatal outcome [5], we think it would be better to perform computed tomography for many subjects with diabetic ketoacidosis.

Author contributions S.K. researched data and wrote the manuscript. H.K. wrote and reviewed/edited the manuscript. A.T., R.S., S.I., Y.H., M.T., K.Ko. M.S., T.M. and K.Ka. researched data and contributed to the discussion.

\section{Compliance with ethical standards}

Conflict of interest The authors declare that there is no conflict of interest associated with this manuscript.

Ethical standard All procedures followed were in accordance with the ethical standards of the responsible national committee on human experimentation and with the Helsinki Declaration of 1975, as revised in 2008 .

Human and animal rights All procedures performed in studies involving human participants were in accordance with the ethical standards of the national research committee and with the 1964 Helsinki declaration and its later amendments or comparable ethical standards.
Informed consent Informed consent was obtained from the reported patient.

Open Access This article is distributed under the terms of the Creative Commons Attribution 4.0 International License (http://crea tivecommons.org/licenses/by/4.0/), which permits unrestricted use, distribution, and reproduction in any medium, provided you give appropriate credit to the original author(s) and the source, provide a link to the Creative Commons license, and indicate if changes were made.

\section{References}

1. Zapardiel I, Delafuente-Valero J, Diaz-Miguel V, Godoy-Tundidor V, Bajo-Arenas JM (2009) Pneumomediastinum during the fourth stage of labor. Gynecol Obstet Invest 67:70-72

2. Bullaboy CA, Jennings RB Jr, Johnson DH, Coulson JD, Young LW, Wood BP (1989) Radiological case of the month. Pneumomediastinum and subcutaneous emphysema caused by diabetic hyperpnea. Am J Dis Child 143:93-94

3. Pooyan P, Puruckherr M, Summers JA, Byrd RP Jr, Roy TM (2004) Pneumomediastinum, pneumopericardium, and epidural pneumatosis in DKA. J Diabetes Complicat 18:242-247

4. Sahebjami H, Vassallo CL, Wirman JA (1978) Lung mechanics and ultrastructure in prolonged starvation. Am Rev Resp Dis 117:77-83

5. Kaneki T, Kubo K, Kawashima A, Koizumi T, Sekiguchi M, Sone S (2000) Spontaneous pneumomediastinum in 33 patients: yield of chest computed tomography for the diagnosis of the mild type. Respiration 67:408-411 